\title{
Exploration of Computer Information Construction and Management Problems
}

\author{
Yongsong Huang \\ Hunan Vocational College of Modern Logistics, Changsha Hunan, 410131, China
}

Key words: Computer, Information, Construction, Management, Problem.

\begin{abstract}
In current stage, the application fields of computer information technology expand continuously based on the development of modern science and technology. Meanwhile, information technology is not just science and technology, but also plays an irreplaceable role in the aspect of school management and comprehensive competitiveness. Hence, for school management level, it is more important to construct and manage computer information. It is a problem which needs to be solved urgently in school development process. Thus, this paper regards computer information as the research emphasis and expounds the problems about construction and management, in the hope of laying a solid foundation for sustainable development of the school.
\end{abstract}

\section{Introduction}

Under the background of comprehensive popularization of computer technology, human society gradually enters information age. To achieve stable and sustainable development in this environment, schools must take full advantage of computer technology to rationally change traditional management mode, enhance construction and management of school computer information and make sure computer information network serves for schools. On this basis, school management work should adapt to the development demand of modern society under the effect of computer information. Thus, schools should overall enhance their management level, improve comprehensive competitive strength and finally facilitate progress and development of school information.

\section{Overview of computer information construction}

As everyone knows, science and technology are the primary productive forces. Hence, productive force is the key to sustainable development. Under the background of information age, computer application technology and information construction gradually become the carrier of school competitiveness. School information construction refers to full utilization of computer technology and network technology to finally achieve overall improvement of teaching research and management decision efficiency and enhance school competitiveness ${ }^{[1]}$. ERP effectively integrates human flow, material flow and information flow, involves customer service structure and rationally applies graphic user interface. School information construction is different from traditional construction project evaluation. Its complexity is very obvious. The construction demand will present periodical change trend with the school development.

\section{Practical significance of computer information construction and management}

\section{To lay an important foundation for improving core competitiveness of schools}

Core competitiveness of schools refers to the unique ability of teaching research and student management etc. Core competitiveness takes technical capacity of schools as the emphasis and 
organically integrates teaching research, student management, strategic decision-making and organizational management so as to make sure competitive edge of schools improve continuously.

Under the background of modern society, development speed of knowledge economy and information accelerates continuously. So, computer application technology and information show the important functions in school information transfer and communication, and can effectively improve school operation efficiency. Besides, they are also the foundation for achieving transnational cooperation. It is required to combine school development conditions, overall construct computer application technology and information, deeply develop and utilize information resources, which can improve school management, enhance school competitiveness and economic benefit and promote stable and sustainable development of schools ${ }^{[2]}$.

\section{To facilitate external communication and exchange}

External communication refers to information transfer and exchange process of schools with external environment. Under the background of information economy era, information plays a key role and its function cannot be ignored in future school development. Thus, strong schools must overall grasp the important functions of computer application technology and information construction, carry out real-time exchange and communication with the external world so as to gain comprehensive information content. On this basis, computer application technology and information construction should be valued in the communication process and regarded as the school advantages to overall collect school information and occupy the advantage in competitions. In addition, schools should fully consider their development conditions according to the information acquired, and deeply study innovative thought and decision so as to make sure schools gain development power and improve their core competitiveness.

\section{Important preconditions of school resource management}

Traditional information feedback mode usually requires schools to deeply analyze teaching research and student management situation. So, it is very hard to accurately grasp the school conditions in a short time and make corresponding adjustments of school management. At the same time, the problems of traditional management mode are also prominent and increase economic losses of schools ${ }^{[3]}$. On this basis, the sensitivity of most schools is insufficient in capital flow process. Thus, it is difficult to overall optimize school fund management. Finally, fund and information waste increases.

\section{Demand of school basic management}

At present, schools also have many defects internally, such as serious shortage of basic data information and inaccurate student management and teaching research data. The above problems seriously affect school precision management. Besides, scientific rationality is not obvious in management and use of student management and teaching research funds. On this basis, financial information and student management information are difficult to achieve synchronization with daily change information. Meanwhile, it is hard to fully embody the authenticity of financial data information. Finally, decision maker's cognition and understanding of financial conditions are restricted. The effect of measures and schemes cannot be ensured. Based on numerous defects in basic management work, computer technology is required.

\section{Current problems of computer information construction and management}

At present, most schools have adopted information management mode. However, there are always defects in information construction and management. Thus, it is necessary to adopt measures in time to achieve the development goal. The problems of school computer information construction and management are reflected in the following aspects:

Firstly, some school leaders and workers fail to rationally treat information construction and management and bring it in school work. On the contrary, they consider information management is 
to apply multiple modern computer technologies, and they just need to correctly operate and use modern office devices.

Secondly, many schools lag behind relatively in terms of systems and management measures and fail to form sound constraint and promotion mechanism. At the same time, they fail to deeply understand and grasp the application method of information software, and it is hard to achieve deep expansion. In such case, the application of information technology in information management lacks practical effect ${ }^{[4]}$.

Thirdly, the number of professionals in internal information education and management is small, so the effects of technical support and personnel potential are not ideal. It is hard to achieve sustainable development of information construction and management.

\section{Effective ways to improve computer information construction and management}

\section{To overall grasp the key points of information construction and management}

In current stage, for school information construction and management, the type of advanced technologies is not the sole factor which decides technical level of a school. It is also influenced by the ability of internal workers to grasp information and apply the computer. Although schools have invested heavily in the technology, the innovation of technology is not obvious. Thus, schools need to grasp the key points, overall enhance the ability of internal workers to apply computer technology, improve their comprehensive quality and achieve overall optimization of resource allocation.

\section{To improve the ability of internal workers to apply information and computer technology}

Talents play a very crucial role in sustainable development of schools, especially in the aspect of information and computer application technology. Thus, schools must overall enhance the ability of internal workers to apply information and computer technology and further improve information management work. On this basis, schools need to overall train high-quality talents to make sure they own strong information management ability. Moreover, schools should cultivate comprehensive talents through multiple methods such as external exchange and introduction so as to offer valuable theoretical basis for achieving information management objective.

\section{To accurately seek breakthroughs of information}

In the construction process of school information and computer application technology, schools must correctly choose the breakthroughs according to the pre-established principles so as to overall implement information construction. However, different schools have imbalance problem in the development aspect, so different problems will occur. In such case, it is necessary to fully consider school development situation and make plans rationally in the process of computer technology process. Most importantly, it is required to regard unique advantages of schools as the starting point to increase the success probability of information construction. Furthermore, it is required to deem different points of teaching research and student management as the key points, enhance the weak link, effectively boost school management level and further drive stable and sustainable development of schools.

\section{To rationally formulate the measures for computer application technology and information construction}

In the construction process of computer information and application technology, school development objective should be clear. Meanwhile, the main reasons for the construction should be deeply understood so as to guarantee comprehensive grasp of mechanism construction for information and computer application technology. In addition, management staffs should accurately grasp current school environment and strategy and carry out comprehensive analysis of multiple factors such as detailed demand for information and key service process so as to ensure correct cognition of school advantages and disadvantages. Schools also should analyze challenges, seize the development 
opportunity and lay a solid foundation for sustainable development of schools ${ }^{[5]}$. On this basis, it is also required to know the connection and difference among factors. Only in this way, comprehensive optimization of resource allocation can be achieved, and resource driving force can be exerted effectively. Meanwhile, information management work can be further driven, and technical guarantee can be offered for school progress and stable development.

\section{To establish and improve the operation system of information and computer application technology}

As is well-known, it will take a long time for construction of information and computer application technology, so complete management system must be constructed in the school. The management system must include analysis experts and planning experts. Meanwhile, computer experts and management exerts also participate. On this basis, construction of information and computer application technology should be implemented actively to make sure the construction funds of each project are in place. Under the background of overall construction of information and computer application technology, it is necessary to carry out comprehensive analysis of student management, teaching research, school finance, technology and economy and make budgets. It is required to make the construction funds of information and computer application technology sufficient through multiple financing channels and further drive basic management work of schools. Besides, in the construction process of information and computer application technology, comprehensive office web portal should be set up to overall expand the cooperation field. Similarly, school management information system should be established to lay a solid foundation for smooth implementation of internal information management.

\section{To enhance school network security}

Based on the development of network technology, network security gradually becomes the key point of school information management work. So, schools need to attach importance to network security construction and achieve all-round supervision and control through reasonable measures. Schools may pursue and install network firewall and should update it in time. As well, schools may upgrade relevant security software to achieve all-round protection of network security and promote school information construction.

\section{To rationally plan information construction link}

In terms of computer information construction and management, schools must actively implement overall planning strategy from the global perspective in order to guarantee the rationality of objective. Schools need to actively construct system mechanism to overall optimize functions of computer system and improve information structure mechanism. On this basis, schools can clearly know the overall standard and architecture, and then formulate the specific standards of information technology according to relevant norms. The main purpose is to improve the effect of computer application technology and information construction.

\section{To value benefits of school staffs}

As information level gradually improves in China, people's living quality also improves. Thus, people continuously increase the requirements for spiritual service in work and life, except basic needs. Meanwhile, educational level improves in China, so citizens' cultural quality also improves. In such case, people pursue self-actualization. Through full utilization of computer technology and information construction, ideal working environment can be created for school staffs, and schools can correctly guide them to achieve self-management and improvement so that they can excavate their potential in the specific positions, enhance their work enthusiasm and better make contributions to school development. 


\section{Conclusions}

In conclusion, computer information construction and management play a very important role in schools. Similarly, the work of computer information construction and management is strategic and systematic work. In the aspect of information construction and management, schools will encounter many difficulties. Thus, schools must take actions to improve in an all-round way, this paper mainly studies and analyzes the problems about computer information construction and management as well as proposes many improvement measures, in the hope of providing valuable theoretical foundation for school computer information construction and management.

\section{References}

[1] Liu Yu, Analysis on Problems and Countermeasures of Accounting Information Construction, Accountant, 2015(17):58-59.

[2] Deng Xiaoxia, Duan Guoyun, Design and Exploration on Data Center of University Education Informatization Construction, Modern Computer (Professional Edition), 2015(23):40-43.

[3] Ding Lanlan, Discussion on Enterprise Archive Information Construction and Management, China High-Tech Enterprises, 2016(14):154-155.

[4] Jiang Mingjie, Analysis on Common Problems and Optimization Countersues of Rural Financial Management Information Construction, Super Science, 2015(24):225-226.

[5] Li Guiping, Tang Meiyan, Effects, Problems and Countermeasures of Hospital Care Information Construction, Medical Information, 2014(39):154-154. 